\title{
Charcot-Marie-Tooth disease type 4J
}

INSERM

\section{Source}

INSERM. (1999). Orphanet: an online rare disease and orphan drug data base. CharcotMarie-Tooth disease type 4J. ORPHA:139515

Charcot-Marie-T ooth disease type $4 \mathrm{~J}$ is a subtype of Charcot-Marie-T ooth disease type 4 characterized by childhood- to adulthood-onset of variably severe, rapidly progressive, axonal and demyelinating sensorimotor neuropathy typically manifesting with delayed motor development, proximal and distal asymmetric muscle weakness and atrophy of the lower and upper extremities, severe motor dysfunction with mildly reduced sensory impairment, and areflexia. Nerve conduction velocities range from very mildly to severely reduced. 